\title{
Laccase recovery with aqueous two-phase systems: Enzyme partitioning and stability
}

\author{
S.C. Silvério ${ }^{\mathrm{a}, \mathrm{b}}$, O. Rodríguez ${ }^{\mathrm{a}}$, A.P.M. Tavares ${ }^{\mathrm{a}}$, J.A. Teixeira ${ }^{\mathrm{b}}$, E.A. Macedo $^{\mathrm{a}, *}$ \\ a LSRE - Laboratory of Separation and Reaction Engineering - Associate Laboratory LSRE/LCM, Faculdade de Engenharia, Universidade do Porto, \\ Rua Dr. Roberto Frias, 4200-465 Porto, Portugal \\ ${ }^{\mathrm{b}}$ IBB - Institute for Biotechnology and Bioengineering, Centre of Biological Engineering, Universidade do Minho, Campus de Gualtar, 4710-057 Braga, Portugal
}

\section{A R T I C L E I N F O}

\section{Article history:}

Received 18 May 2012

Received in revised form

28 September 2012

Accepted 21 October 2012

Available online $\mathrm{xxx}$

\section{Keywords:}

Aqueous two-phase systems

Laccase

Partition coefficient

Enzymatic stability

\begin{abstract}
A B S T R A C T
In this work, the potential of several aqueous two-phase systems (ATPS) for laccase recovery was evaluated. For this purpose, different types of ATPS were prepared and the partition coefficient of pure commercial laccase was determined in each one, at $23^{\circ} \mathrm{C}$. A total of 21 ATPS were investigated: $12 \mathrm{com}-$ posed by a polymer and a salt and 9 composed by two different polymers. For polymer-salt ATPS, different compositions of the same biphasic system were also studied. Laccase partition coefficients $(K)$ obtained were used to conclude about ATPS effectiveness for this enzyme recovery. According to the results, it was found that UCON-phosphate salts $(K \leq 0.604), \mathrm{PEG}-\mathrm{Li}_{2} \mathrm{SO}_{4}(K=2.081)$ and PES-dextran $(K=1.911)$ ATPS can be interesting options for laccase extraction, with laccase partitioning toward opposite directions. However, the most effective ATPS for laccase extraction was UCON- $\mathrm{K}_{2} \mathrm{HPO}_{4}$, presenting $K$ values from 0.272 up to 0.306 . UCON is a thermo-separating polymer which facilitates its recovery and reutilization. Additionally, for the first time, laccase stability in different ATPS was investigated by incubating the enzyme in each equilibrium phase during a week, at room temperature. The results obtained showed that UCON-sulfate salts, $\mathrm{UCON}-\mathrm{NaH}_{2} \mathrm{PO}_{4}$ and $\mathrm{UCON}-\mathrm{KH}_{2} \mathrm{PO}_{4}$ ATPS are not recommended for laccase recovery since a high loss of activity was observed: approximately $88 \%$ for sulphates and $80 \%$ for both dihydrogen phosphates. The best stability results were obtained with PEG-sulfate salts. For these ATPS, laccase stability remained similar or improved over time.
\end{abstract}

(c) 2012 Elsevier B.V. All rights reserved.

\section{Introduction}

Laccases (benzenediol: oxygen oxidoreductase, EC 1.10.3.2) belong to a small group of enzymes called the blue copper oxidases. These enzymes contain four catalytic copper atoms distributed in three redox sites and are able to catalyze the oxidation of several organic compounds ( $o$ - and $p$-diphenols, aminophenols, polyphenols, polyamines, lignins, methoxy phenols, aryl diamines, among others) [1-3] as well as some inorganic ions [4-6] with the simultaneous reduction of molecular dioxygen to water and without intermediate production of hydrogen peroxide.

Originally described in plants [7], laccases can also be found in fungi and bacteria [8]. Fungal laccases have higher redox potential than bacterial or plant laccases, and their action seems to be relevant in nature (namely in the degradation of lignin) finding also some important applications in biotechnology. Laccases are highly regarded as environmentally friendly enzymes and an alternative to conventional oxidation technologies [9]. Enzymatic oxidation

\footnotetext{
* Corresponding author.

E-mail address: eamacedo@fe.up.pt (E.A. Macedo).
}

has advantages over chemical oxidation because reactions are carried out in mild conditions and enzymes are biodegradable and highly specific catalysts. The white-rot fungus Trametes versicolor is one of the most studied species for laccase production. Laccase from T. versicolor was reported to have the highest redox potential among laccases ( $785 \mathrm{mV}$ versus the standard hydrogen electrode [10]). This fact makes $T$. versicolor laccase particularly interesting since high redox potentials are connected with high oxidative capability. These characteristics together with the broad substrate specificity make laccase from $T$. versicolor a promising enzyme for industrial applications [11]. During the last decades, new and attractive methodologies involving its oxidation capacity have been used in different areas such as: textile industries [12-14], pulp and paper industry [15,16], soil bioremediation [17], nanobiotechnology and biosensors [18-20], synthetic chemistry [21], and cosmetics [22].

However, for all these industrial applications considerable amounts of enzyme are necessary and generally high purity is required. Fermentation is the most attractive and feasible method for laccase production but its recovery and purification from fermentation broths commonly involves several steps that make the process expensive and time-consuming. The development of new techniques and methods for the separation and purification of 
enzymes has been the key for the advances in the biotechnology industry. Liquid-liquid extraction is an interesting alternative since several features of the early processing steps can be combined into a single operation. This process is widely employed in the chemical industry due to its simplicity, low cost, and ease of scale up. However, the use of liquid-liquid extraction employing organic solvents is limited because of biomolecules denaturation. Biomolecules need a mild environment which can be achieved using extraction with aqueous two-phase systems (ATPS).

ATPS are biphasic systems obtained by mixing two aqueous solutions of different constituents that become immiscible above certain critical conditions (like temperature, concentration, etc.). Both immiscible phases are composed mainly by water $(>80 \%)$ and each one is enriched in a different component [23]. ATPS formed by polymer-polymer or polymer-salt represent the traditional systems [24]. However, alternative biphasic systems can be obtained using surfactants, micellar compounds [25] or ionic liquids [26]. During the last decades, ATPS have received considerable attention as an alternative recovery process. ATPS provide an excellent environment for biological products [27], and have been used for the recovery of biocompounds from different biological sources (biological suspensions, fermentations broths, commercial sources). Applications for recovery of both low/high-value products with acceptable process yields (65-100\%) can be also found, demonstrating the flexibility, robustness and potential generic application of this technique $[28,29]$. Lacasse recovery from fermentation broths using ATPS or even the use of extractive fermentation in an ATPS (the so-called process integration) could be promising alternatives to the conventional techniques. Nevertheless, to successfully employ ATPS in laccase recovery, a preliminary study has to be done in order to find a suitable ATPS. The conditions for this suitability are that the ATPS ensures satisfactory enzyme recovery and does not compromise the enzymatic activity and stability.

In this work, partition coefficients of commercial laccase from T. versicolor were determined in 21 different ATPS: 12 composed by a polymer and a salt and 9 composed by two different polymers. For polymer-salt ATPS, different compositions of the same biphasic system (different tie-lines) were also studied. The partition coefficients of pure laccase were used to evaluate the potential of each system and to conclude about its suitability for enzyme recovery from fermentation broths. Besides, for the first time, laccase stability was studied in ATPS. For this purpose, laccase was incubated in each equilibrium phase and the enzymatic activity was followed during a week. This procedure allowed to investigate the effect of ATPS constituents in laccase activity and assess the potential of the ATPS for in situ recovery in a fermentation process.

\section{Material and methods}

\subsection{Chemicals}

Polysaccharide Ficoll PM70 (average molecular weight 70000) was provided from GE Healthcare Biosciences AB (Sweden). Hydroxypropyl starch, Reppal PES-100 (average molecular weight 100000), was purchased from Reppe AB (Sweden). Dextran 75 (average molecular weight 75000) was obtained from USB. UCON 50-HB-5100, a random copolymer (average molecular weight 3900 ) of $50 \%$ ethylene oxide and $50 \%$ propylene oxide, was obtained from Union Carbide (NY, USA). Polyethylene glycol, PEG (average molecular weight 8000), and laccase from T. versicolor were purchased from Sigma (Spain). Sodium sulfate $\left(\mathrm{Na}_{2} \mathrm{SO}_{4}\right.$, anhydrous GR for analysis, $>99.0 \%$ ), sodium chloride ( $\mathrm{NaCl}, \mathrm{GR}$ for analysis, >99.5\%), ammonium sulfate $\left(\left(\mathrm{NH}_{4}\right)_{2} \mathrm{SO}_{4}\right.$, Suprapur, $>99.9999 \%)$, dipotassium hydrogen phosphate $\left(\mathrm{K}_{2} \mathrm{HPO}_{4}\right.$, anhydrous, $99.99 \%$ Suprapur), sodium dihydrogen phosphate dihydrate
$\left(\mathrm{NaH}_{2} \mathrm{PO}_{4} \cdot 2 \mathrm{H}_{2} \mathrm{O}\right.$, p.a., Reag. Ph Eur) and disodium hydrogen phosphate $\left(\mathrm{Na}_{2} \mathrm{HPO}_{4}\right.$, anhydrous, GR for analysis, ACS, Reag. Ph Eur) were obtained from Merck (Germany). Lithium sulfate $\left(\mathrm{Li}_{2} \mathrm{SO}_{4}\right.$, purum p.a., $>98.0 \%$ ) and potassium dihydrogen phosphate $\left(\mathrm{KH}_{2} \mathrm{PO}_{4}\right.$, Ph Eur) were supplied by Fluka (USA). 2,2'-azino-bis(3ethylbenzthiazoline-6-sulfonic acid) diammonium salt (ABTS, 98\%) was obtained from Sigma (Spain) and used as substrate for laccase.

All products were used as received without further purification. Stock solutions of each chemical were prepared in deionized water, and all concentrations were obtained gravimetrically after evaporation on a heating plate (Stuart hot plate SB300) for salts or after lyophilization (Scan Vac, model CoolSafe 55-4) for the polymers. Potassium phosphate buffer (KPB, $1 \mathrm{M}, \mathrm{pH}=7.0$ ) was obtained by combining the $\mathrm{KH}_{2} \mathrm{PO}_{4}$ and $\mathrm{K}_{2} \mathrm{HPO}_{4}$ salts. Sodium phosphate buffer ( $\mathrm{NaPB}, 1 \mathrm{M}, \mathrm{pH}=7.0$ ) and ( $\mathrm{NaPB}, 1 \mathrm{M}, \mathrm{pH}=7.4$ ) were prepared combining the $\mathrm{NaH}_{2} \mathrm{PO}_{4}$ and $\mathrm{Na}_{2} \mathrm{HPO}_{4}$ salts. Buffer concentrations were obtained gravimetrically after evaporation on a heating plate. The $\mathrm{pH}$ value was confirmed using a pH meter (VWR, SimpHony SB70P). Deionized water was used for all diluting purposes. All weighing was carried out on an Adam Equipment balance model AAA250L, precise to within $\pm 0.2 \mathrm{mg}$.

\subsection{Methods}

\subsubsection{Laccase partition}

Laccase partition coefficients were measured experimentally, at $23^{\circ} \mathrm{C}$, in several ATPS available in the literature [24,30-34]. Final compositions for the ATPS are indicated in Table 1 . To obtain each biphasic system, appropriated amounts of polymers or polymer and salt stock solutions were mixed in $2 \mathrm{~mL}$ eppendorf using an automatic pipette (Multipette ${ }^{\circledR}$ Xstream, Eppendorf). For each ATPS, six replicates with the same feed composition but containing from 0 up to $200 \mathrm{mg}$ of a laccase stock solution $\left(5 \mathrm{mg} \mathrm{mL}^{-1}\right)$ were prepared. The corresponding amount of water (from 200 to $0 \mathrm{mg}$ ) was added to keep all compositions constant, except for laccase, and assess aggregation effects. The tubes were then thoroughly mixed on a vortex mixer for $2 \mathrm{~min}$, and phase separation was achieved by centrifugation $\left(10^{4} \mathrm{rpm}\right.$ for $\left.15 \mathrm{~min}\right)$. Samples of each phase were withdrawn and conveniently diluted, and the absorbance at $280 \mathrm{~nm}$ was measured using a UV-vis spectrophotometer (Thermo Electron Corp., model UV1). All absorbances were below 0.8. Concentration of laccase was calculated from calibration curves previously obtained for top and bottom phases. The partition coefficient was calculated as the slope of the straight line obtained when comparing the concentration ( $\mathrm{mg} \mathrm{mL}^{-1}$ ) in the top (or polymer-rich) phase against that in the bottom (or salt-rich) phase, corrected with the corresponding dilution factor, $\mathrm{DF}_{\text {phase }}$ (the final volume divided by the initial volume), thus:

$$
K=\frac{\text { Conc.(top) } \times \mathrm{DF}_{\text {top }}}{\text { Conc.(bottom) } \times \mathrm{DF}_{\text {bottom }}}
$$

\subsubsection{Laccase stability at different $p H$}

In order to determine the optimal $\mathrm{pH}$ for laccase stability, several buffers $(0.1 \mathrm{M})$ with different $\mathrm{pH}$ values were prepared: acetate buffers for the range 3.0-5.5, phosphate buffers for the range 6.0-8.0 and carbonate buffers for the range 9.0-10.0. Enzyme stability was evaluated, at room temperature, during a week by incubating $1 \mathrm{~mL}$ of laccase stock solution $\left(0.8 \mathrm{mg} \mathrm{mL}^{-1}\right.$ in deionized water) and $9 \mathrm{~mL}$ of each buffer into capped vials. Laccase activity was determined spectrophotometrically at $420 \mathrm{~nm}$ using ABTS $0.4 \mathrm{mM}$ as substrate $\left(\varepsilon=36 \times 10^{3} \mathrm{M}^{-1} \mathrm{~cm}^{-1}\right)$ in $0.05 \mathrm{M}$ citrate $/ 0.1 \mathrm{M}$ phosphate buffer at $\mathrm{pH} 4.5$ and $40^{\circ} \mathrm{C}$ [35]. One unit of activity is defined as the amount of enzyme required to obtain $1 \mu \mathrm{mol}$ of the oxidized product per minute. The initial activities were measured immediately after the addition of the enzyme into the incubation 
Table 1

ATPS composition and laccase partition coefficients $(K)$ experimentally obtained.

\begin{tabular}{|c|c|c|c|}
\hline & Polymer wt\% & Salt wt\% & $K$ \\
\hline \multicolumn{4}{|l|}{ UCON-phosphate salt } \\
\hline UCON-NaH ${ }_{2} \mathrm{PO}_{4}$ (TLA) [30] & 16.00 & 6.50 & $0.580 \pm 0.004$ \\
\hline $\mathrm{UCON}-\mathrm{NaH}_{2} \mathrm{PO}_{4}(\mathrm{TLB})^{\mathrm{a}}[30]$ & 18.26 & 6.99 & $0.589 \pm 0.004$ \\
\hline UCON-NaH ${ }_{2} \mathrm{PO}_{4}$ (TLC) [30] & 20.00 & 8.00 & $0.604 \pm 0.003$ \\
\hline UCON-NaPB pH7 (TLA) [30] & 15.97 & 3.91 & $0.347 \pm 0.002$ \\
\hline UCON-NaPB pH7 (TLB) ${ }^{\mathrm{a}}[30]$ & 17.24 & 4.30 & $0.354 \pm 0.001$ \\
\hline UCON-NaPB pH7 (TLC) [30] & 18.59 & 4.70 & $0.359 \pm 0.002$ \\
\hline UCON-Na $\mathrm{HPO}_{4}$ (TLA) [30] & 14.91 & 3.50 & $0.439 \pm 0.002$ \\
\hline UCON-Na ${ }_{2} \mathrm{HPO}_{4}(\mathrm{TLB})^{\mathrm{a}}[30]$ & 16.01 & 3.90 & $0.385 \pm 0.003$ \\
\hline UCON-Na ${ }_{2} \mathrm{HPO}_{4}$ (TLC) [30] & 17.30 & 4.30 & $0.368 \pm 0.002$ \\
\hline UCON-KH${ }_{2} \mathrm{PO}_{4}$ (TLA) [30] & 15.00 & 7.00 & $0.542 \pm 0.002$ \\
\hline $\mathrm{UCON}-\mathrm{KH}_{2} \mathrm{PO}_{4}(\mathrm{TLB})^{\mathrm{a}}[30]$ & 17.20 & 7.60 & $0.531 \pm 0.002$ \\
\hline $\mathrm{UCON}-\mathrm{KH}_{2} \mathrm{PO}_{4}$ (TLC) [30] & 18.99 & 8.50 & $0.524 \pm 0.002$ \\
\hline UCON-KPB pH7 (TLA) [30] & 13.01 & 5.30 & $0.524 \pm 0.004$ \\
\hline UCON-KPB pH7 (TLB) ${ }^{\mathrm{a}}[30]$ & 14.01 & 5.70 & $0.469 \pm 0.002$ \\
\hline UCON-KPB pH7 (TLC) [30] & 15.02 & 6.10 & $0.424 \pm 0.003$ \\
\hline $\mathrm{UCON}-\mathrm{K}_{2} \mathrm{HPO}_{4}(\mathrm{TLA})[30]$ & 18.02 & 3.80 & $0.306 \pm 0.001$ \\
\hline $\mathrm{UCON}-\mathrm{K}_{2} \mathrm{HPO}_{4}(\mathrm{TLB})^{\mathrm{a}}[30]$ & 19.98 & 4.00 & $0.286 \pm 0.001$ \\
\hline $\mathrm{UCON}-\mathrm{K}_{2} \mathrm{HPO}_{4}(\mathrm{TLC})[30]$ & 22.00 & 4.20 & $0.272 \pm 0.001$ \\
\hline \multicolumn{4}{|l|}{ UCON-sulfate salt } \\
\hline $\mathrm{UCON}-\left(\mathrm{NH}_{4}\right)_{2} \mathrm{SO}_{4}[31]$ & 12.60 & 6.50 & $1.077 \pm 0.004$ \\
\hline $\mathrm{UCON}-\mathrm{Li}_{2} \mathrm{SO}_{4}[32]$ & 12.00 & 5.70 & $1.467 \pm 0.006$ \\
\hline UCON-Na ${ }_{2} \mathrm{SO}_{4}[32]$ & 16.76 & 4.13 & $0.685 \pm 0.004$ \\
\hline \multicolumn{4}{|l|}{ PEG-sulfate salt } \\
\hline PEG-(NH4) $)_{2} \mathrm{SO}_{4}[24]$ & 12.50 & 11.00 & $1.362 \pm 0.005$ \\
\hline PEG- $\mathrm{Li}_{2} \mathrm{SO}_{4}[32]$ & 14.00 & 10.00 & $2.081 \pm 0.009$ \\
\hline PEG-Na ${ }_{2} \mathrm{SO}_{4}$ (TLA) [33] & 11.29 & 6.94 & $0.876 \pm 0.003$ \\
\hline PEG-Na ${ }_{2} \mathrm{SO}_{4}(\mathrm{TLC})^{\mathrm{a}}[33]$ & 11.86 & 7.27 & $0.928 \pm 0.004$ \\
\hline PEG-Na ${ }_{2} \mathrm{SO}_{4}$ (TLE) [33] & 12.79 & 8.38 & $1.102 \pm 0.005$ \\
\hline
\end{tabular}

Polymer(1) wt\% Polymer(2) wt\% $K$

\begin{tabular}{lrrl}
\hline Polymer-polymer $^{\mathrm{b}}$ & & & \\
Dextran(1)-Ficoll(2) [34] & 12.94 & 18.06 & $1.216 \pm 0.006$ \\
Dextran(1)-PEG(2) [34] & 12.41 & 6.06 & $0.939 \pm 0.006$ \\
Dextran(1)-UCON(2) [34] & 12.39 & 10.08 & $0.487 \pm 0.003$ \\
Ficoll(1)-PEG(2) [34] & 15.06 & 7.90 & $0.651 \pm 0.003$ \\
Ficoll(1)-UCON(2) [34] & 13.01 & 9.93 & $0.820 \pm 0.007$ \\
PES(1)-Dextran(2) [34] & 17.30 & 12.43 & $1.911 \pm 0.010$ \\
PES(1)-Ficoll(2) [34] & 17.31 & 14.86 & $1.305 \pm 0.008$ \\
PES(1)-PEG(2) [34] & 15.24 & 6.96 & $0.782 \pm 0.004$ \\
PES(1)-UCON(2) [34] & 12.91 & 7.68 & $1.033 \pm 0.005$ \\
\hline
\end{tabular}

$\mathrm{NaPB}$, sodium phosphate buffer; KPB, potassium phosphate buffer.

a Composition used in the enzymatic stability assay.

b $\mathrm{NaCl}$ and $\mathrm{NaPB} \mathrm{pH} 7.4$ were also added to achieve $0.15 \mathrm{M}$ and $0.01 \mathrm{M}$, respectively.

media (final concentration ca. $1500 \mathrm{U} / \mathrm{L}$ ). The residual activities were evaluated at regular time intervals during a week. For each activity measurement, two samples were analyzed and the average value was considered. In all cases relative standard deviations (RSD) below $10 \%$ were obtained.

\subsubsection{Laccase stability in ATPS}

For all ATPS (Table 1), systems with $5 \mathrm{~g}$ total weight were prepared in falcon tubes and vigorously mixed in the vortex prior to achieve phase separation using centrifugation $\left(6^{4} \mathrm{rpm}\right.$ for $15 \mathrm{~min}$ ). After that, top and bottom phases were collected and stored refrigerated. Enzyme stability was evaluated by incubating, at room temperature, $35 \mu \mathrm{L}$ laccase stock solution $(2.2 \mathrm{mg} / \mathrm{mL}$ in deionized water) and each specific phase $(920 \mu \mathrm{L})$ into capped vials. Laccase activity was determined spectrophotometrically as described above for laccase stability at different $\mathrm{pH}$. Control assay was prepared replacing the specific phase by $0.1 \mathrm{M}$ phosphate buffer $\mathrm{pH}$ 7.5. The initial activities were measured immediately after the addition of the enzyme into the incubation media (final concentration $c a .1500 \mathrm{U} / \mathrm{L}$ ). The residual activities were evaluated at regular time intervals during a week. For each activity measurement, two samples were analyzed and the average value was considered. In all cases RSD below $8 \%$ were obtained. Activity variation (\%) was calculated using the initial activity value obtained for each ATPS phase (top or bottom).

\section{Results and discussion}

\subsection{Partition coefficient}

Laccase partitioning was studied in 21 different ATPS: 12 composed by a polymer and a salt and 9 composed by two different polymers. For each biphasic system, six replicates with different laccase concentrations were prepared. A straight line was obtained when laccase concentration in the top phase (or polymer-rich phase) was plotted against laccase concentration in the bottom phase (or salt-rich phase), for the six replicates (data not shown). Laccase partition coefficient $(K)$ was obtained as the slope of this straight line. Linearity was observed in all cases, which indicates that all partition coefficients calculated using this procedure have thermodynamic meaning (since they are independent of the solute concentration). This linearity also confirms that there are no inconvenient phenomena, like aggregation, affecting the partition coefficient.

Laccase partition coefficients obtained in the several ATPS studied, together with the ATPS compositions are presented in Table 1. The partition coefficient $(K)$ quantifies the solute distribution between the equilibrium phases. In ATPS, $K$ is used to evaluate the extension of the separation process. If the target molecule presents a relatively high (or low) $K$, its recovery to the top (or bottom) phase will be effective. $K$ values lower than unity, indicate that laccase partition occurred preferably toward the bottom (or salt-rich) phase. On the other hand, $K$ values higher than unity denote that laccase partition occurred preferably toward the top (or polymer-rich) phase. Finally, $K$ values close to unity signify that laccase partitioning between the equilibrium phases is similar, so the separation in this ATPS will not be effective.

\subsubsection{Influence of the ATPS composition}

The three different compositions (tie-lines) prepared for each UCON-phosphate ATPS and for PEG- $\mathrm{Na}_{2} \mathrm{SO}_{4}$ allowed to study the relationship between $K$ and the composition of the biphasic system. Thus, for UCON-NaH${ }_{2} \mathrm{PO}_{4}$ and UCON-NaPB, when increasing the amount of polymer and salt present in the ATPS (and consequently the tie-line length, TLL), a slight increase in the laccase partition coefficient was observed ( $K$ increased 4 and 3\%, respectively). The increase of the TLL also produced an increase in the $K$ for PEG-Na $\mathrm{SO}_{4}$, but in this case the variation was higher (26\%). On the contrary, for UCON-Na $\mathrm{HPO}_{4}, \mathrm{UCON}-\mathrm{KH}_{2} \mathrm{PO}_{4}, \mathrm{UCON}-\mathrm{KPB}$ and $\mathrm{UCON}-\mathrm{K}_{2} \mathrm{HPO}_{4}$ laccase partitioning to the salt-rich phase increases ( $K$ decreases) as the TLL increases. While for $\mathrm{UCON}-\mathrm{KH}_{2} \mathrm{PO}_{4}$, the increase of the TLL produced only a variation of $3 \%$ in the $K$, for UCON-Na $\mathrm{HPO}_{4}$, UCON-KPB and UCON-K $\mathrm{KPO}_{4}$ the $K$ decreased 16,19 and $11 \%$, respectively.

\subsubsection{Laccase partitioning}

Based on the polymer and salt used to prepare the biphasic systems, polymer-salt ATPS studied can be classified as: UCONphosphate salts, UCON-sulfate salts and PEG-sulfate salts. UCON is a thermo-separating polymer and when heated above its lower critical solution temperature (LCST, about $50^{\circ} \mathrm{C}$ [36]) it separates from the aqueous solution. This characteristic of UCON facilitates polymer recovery and reutilization. PEG is also a thermo-separating polymer, but its LCST is too high (above $100^{\circ} \mathrm{C}$ [37]) and its recycling is not possible when labile molecules are involved.

UCON-phosphate salt ATPS provided the lowest $K$ values, ranging from 0.272 up to 0.604 . For these ATPS, laccase concentration in the salt-rich phase was 2-4-fold that in the polymer-rich phase. Among all the biphasic systems studied, $\mathrm{UCON}-\mathrm{K}_{2} \mathrm{HPO}_{4}$ provided 
the lowest $K$ values, being the most effective ATPS for laccase extraction. The partition coefficient determined for these ATPS ranges from 0.272 up to 0.306 , indicating that laccase concentration in the salt-rich phase is more than three times higher than in the polymer-rich phase. Another important factor to consider is the volume ratio of the phases: for the UCON-K $\mathrm{HPO}_{4}$ ATPS studied, the volume of the salt-rich phase is approximately three times smaller than the polymer-rich phase volume [30]. Thus, if we change the volume ratio by increasing the salt-rich phase volume, the $K$ will remain constant but the amount of enzyme extracted to the saltrich phase will further increase. Thus UCON- $\mathrm{K}_{2} \mathrm{HPO}_{4}$ ATPS has even more potential for an effective laccase recovery.

UCON-sulfate salts ATPS provided higher laccase partition coefficients (0.685-1.467) than the UCON-phosphate ATPS. Besides, for UCON-sulfate ATPS, laccase partitioned to different phases: preferentially to the salt-rich phase with sodium, to the polymer-rich phase with lithium, and almost no partitioning with ammonium sulfate. UCON-( $\left.\mathrm{NH}_{4}\right)_{2} \mathrm{SO}_{4}$ provided a $K$ value close to unity, so this particular ATPS is not recommended for laccase extraction since the separation will not be effective.

The laccase partition coefficients obtained for PEG-sulfate salts ATPS range from 0.876 up to 2.081 . Once more, laccase partitioning in PEG-sulfate salts was variable: to the salt-rich phase with the short sodium tie-line, to the polymer-rich phase with lithium and ammonium, and almost no partitioning with the long and medium tie-lines of sodium. These latter ATPS are not recommended for laccase recovery, for the same reasons mentioned above. On the other hand, $\mathrm{PEG}-\mathrm{Li}_{2} \mathrm{SO}_{4}$ can be an interesting ATPS since it provided a $K$ value around 2 , thus the laccase concentration in the polymerrich phase is twice that in the salt-rich phase.

For polymer-polymer ATPS, $K$ obtained range from 0.487 up to 1.911 , pointing out that laccase partitioning occurred both to bottom and top phase, depending on the system studied. For Dextran-UCON, Ficoll-PEG, PES-PEG and Ficoll-UCON laccase partitioning occurred preferably toward the bottom phase i.e. the Dextran-rich, Ficoll-rich, PES-rich, and Ficoll-rich phase, respectively. For Dextran-Ficoll, PES-Ficoll and PES-Dextran laccase partitioning occurred preferably toward the top phase i.e. Ficollrich phase (Dextran-Ficoll and PES-Ficoll), and Dextran-rich phase (PES-Dextran). Dextran-PEG and PES-UCON provided $K$ values close to unity, so again these ATPS are not recommended for laccase separation. Dextran-UCON and PES-Dextran provided similar enzyme partition but directed toward opposite phases. For Dextran-UCON, $K$ obtained was approximately 0.5 and for PES-Dextran $K$ was close to 2. Both ATPS can be interesting to investigate laccase extraction from fermentation broth.

\subsection{Enzymatic stability}

To determine the optimal pH for laccase stability at room temperature, the enzyme was incubated at several pHs, ranging from 3.0 up to 10.0 , during a week. The enzymatic activity was measured at regular intervals and the results obtained are shown in Fig. 1. The most extreme pHs (3.0-5.0 and 9.0-10.0) provided larger decreases in the enzymatic activity at day 1 . After that, only slight decreases were detected, being the enzymatic activity maintained through the week. For pH 8, laccase activity kept almost constant and close to the initial value during the first days of the assay. However, at the end of the assay a decrease was observed in the enzymatic activity. The highest enzymatic activity values were obtained for the $\mathrm{pH}$ range 6.0-7.5 at the first days of the assay. Nevertheless, on the last days of the assay, a decrease in laccase activity was also observed. This decrease was less pronounced for $\mathrm{pH} 7.5$. For this reason, $\mathrm{pH} 7.5$ was selected as the optimal $\mathrm{pH}$ to be used as control for laccase stability tests performed using the ATPS equilibrium phases.

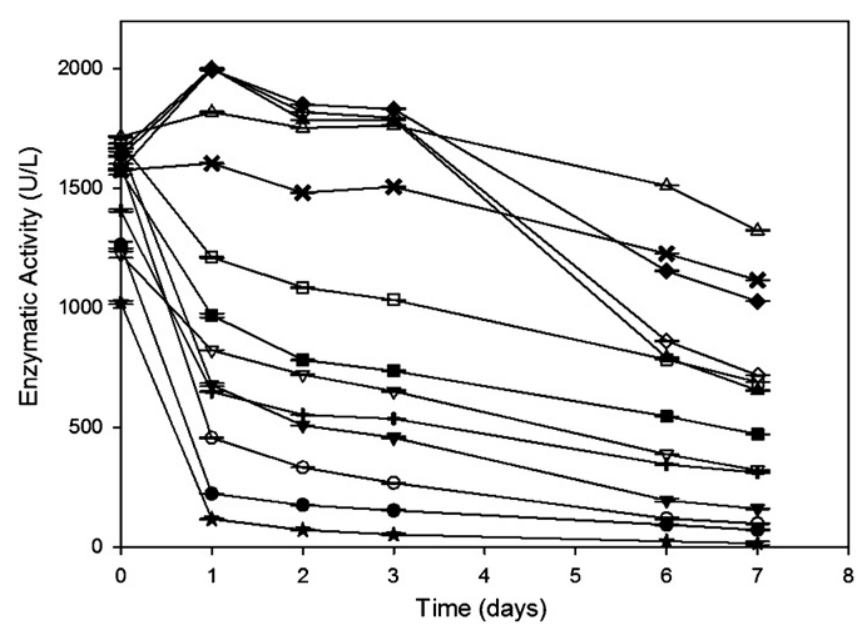

Fig. 1. Effect of $\mathrm{pH}$ on laccase stability, at room temperature. $\bullet \mathrm{pH} 3 ; \bigcirc \mathrm{pH} 3.5$; $\mathbf{\nabla}$ $\mathrm{pH} 4 ; \nabla \mathrm{pH} 4.5 ; \boldsymbol{\mathrm { pH }} 5 ; \square \mathrm{pH} 5.5 ; \diamond \mathrm{pH} 6 ; \diamond \mathrm{pH} 6.5 ; \Delta \mathrm{pH} 7 ; \triangle \mathrm{pH} 7.5 ; \times \mathrm{pH} 8 ;+\mathrm{pH}$ $9 ; \star \mathrm{pH} 10$.

Previous studies demonstrated that ATPS can preserve enzymatic activity and satisfactory stability results were obtained for different proteins for periods of 1-3 days [38-40]. However, a larger period of time is needed to maximize enzyme production in most fermentation processes. Previous studies reported that a maximum laccase production by $T$. versicolor using submerged fermentation in Erlenmeyer can be obtained in 4-8 days, depending on the fermentation conditions [41-43]. When using in situ recovery by extractive fermentation in ATPS, fungal laccase will be in the presence of different ATPS constituents during long periods of time. In this case, it becomes important to ensure enzymatic stability and prevent activity inhibition during the whole fermentation process and a stability study of only 3 days is clearly insufficient. No references were found in literature reporting studies of laccase stability in the ATPS equilibrium phases for long periods of time. To overcome this aspect, we investigated laccase stability in the ATPS used for the partition studies. For this purpose, the enzyme was incubated in each equilibrium phase, at room temperature, during a week. The graphical representation for the enzymatic stability in UCON-sodium phosphate salts and UCON-potassium phosphate salts ATPS is shown in Fig. 2a and b, respectively. The phosphate salts used have different $\mathrm{pH}$ and allowed investigating the influence of the $\mathrm{pH}$ of the salt in the enzymatic stability. According to Fig. 2, similar results were found with sodium and potassium cations. In both cases, the more acidic salts $\left(\mathrm{NaH}_{2} \mathrm{PO}_{4}\right.$ and $\left.\mathrm{KH}_{2} \mathrm{PO}_{4}\right)$ produced the more pronounced decrease in enzymatic activity over time. An activity variation of approximately $80 \%$ was found at the end of the assay for both phases of UCON-NaH $\mathrm{PO}_{4}$ and UCON-KH $\mathrm{HO}_{4}$ ATPS. Therefore, it seems that acidic $\mathrm{pH}$ affects more significantly the laccase stability than higher $\mathrm{pH}$ values. This fact is in agreement with the results obtained in the stability study with different $\mathrm{pH}$ buffers described above and also with literature [44]. Another aspect to highlight is the difference observed for the top and bottom phases of a given ATPS. For all phosphate salts, the bottom phase (salt-rich phase) provided better stability results than the top phase (UCON-rich phase).

Fig. 3 shows the graphical representation for laccase stability with UCON-sulfate salts (a) and PEG-sulfate salts ATPS (b). Comparatively, considerable activity loss was observed for UCON-sulfate salts ATPS. In all cases, activity variations over $88 \%$ were obtained at the end of the assay. However, when UCON is replaced by PEG, enzyme stability remains similar or improves in almost all the biphasic systems studied. For PEG-sulfate salts ATPS the stability results obtained were better than the control ( $\mathrm{pH} 7.5$ ), except 

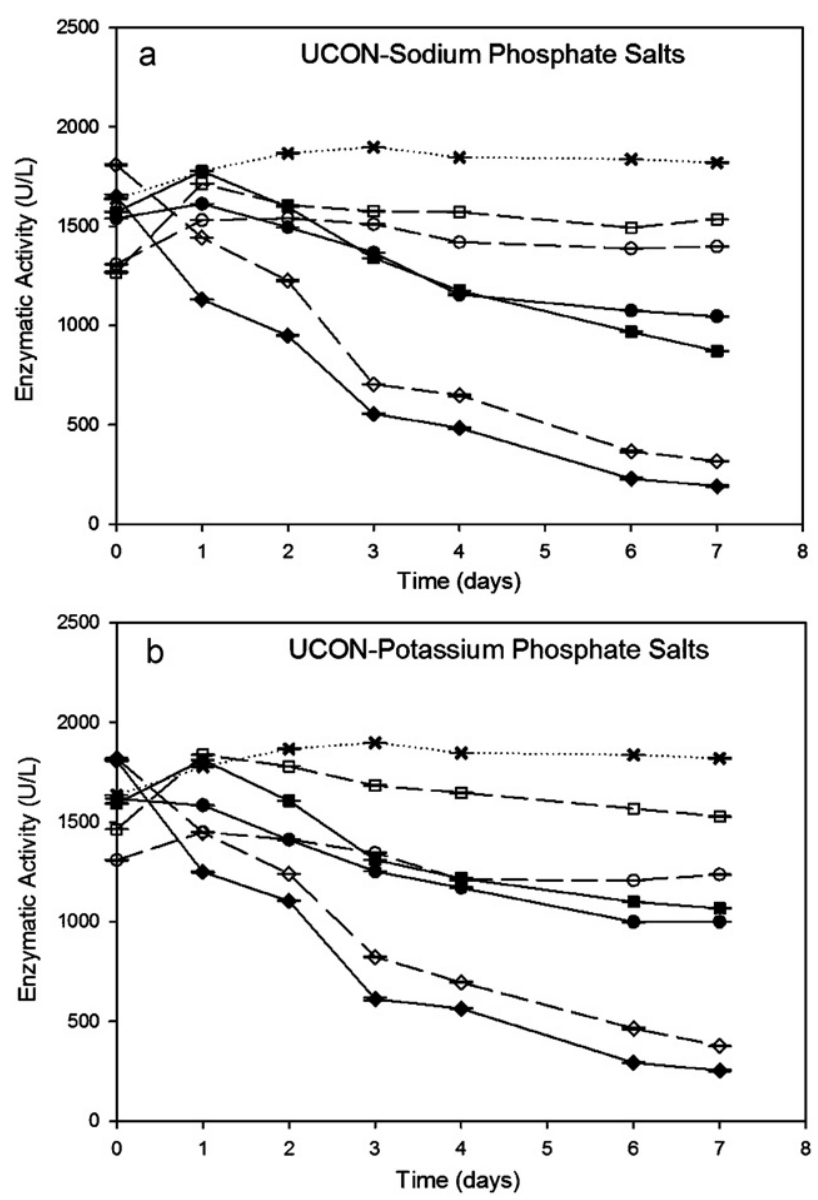

Fig. 2. Laccase stability, at room temperature, in top and bottom phases of UCONphosphate salts ATPS. (a) UCON-sodium phosphate salts: $\mathrm{Na}_{2} \mathrm{HPO}_{4}$ top (filled circle); $\mathrm{Na}_{2} \mathrm{HPO}_{4}$ bottom (open circle); $\mathrm{NaPB}$ top (filled square); NaPB bottom (open square); $\mathrm{NaH}_{2} \mathrm{PO}_{4}$ top (filled diamond); $\mathrm{NaH}_{2} \mathrm{PO}_{4}$ bottom (open diamond); Control pH7.5 (cross). (b) UCON-potassium phosphate salts: $\mathrm{K}_{2} \mathrm{HPO}_{4}$ top (filled circle); $\mathrm{K}_{2} \mathrm{HPO}_{4}$ bottom (open circle); KPB top (filled square); KPB bottom (open square); $\mathrm{KH}_{2} \mathrm{PO}_{4}$ top (filled diamond); $\mathrm{KH}_{2} \mathrm{PO}_{4}$ bottom (open diamond); Control pH7.5 (cross).

for PEG-( $\left.\mathrm{NH}_{4}\right)_{2} \mathrm{SO}_{4}$ which showed some activity loss over time. It is known from the literature that PEG is particularly effective at suppressing the inactivation of several proteins [45-47], including laccase [48]. The stabilization effect of PEG (and other polymers) can be considered as a consequence of enzyme exclusion from part of the solvent. In ATPS, the equilibrium phases are composed mainly by water, but sometimes the phase-forming components (namely the salts) can be present in detrimental concentrations to enzymes. In these cases, polymers can play a protective role, minimizing the prejudicial saline effects and contributing to the enzyme stabilization [49]. This fact may explain the differences in stability observed between PEG-sulfate and UCON-sulfate ATPS. UCON (a random copolymer with ethylene oxide and propylene oxide units) is significantly more hydrophobic than PEG, therefore its interaction with the solvent is lower, affecting enzyme stability over time. Regarding the contribution of the salt to the enzyme stability, it is generally reported that it follows the Hofmeister series [50]. Kosmotropic ions normally stabilize the native conformation of the enzymes and sometimes they can enhance enzyme activity [51]. Ion effects on enzymatic activity may be considered a consequence of conformational changes induced in the enzyme structure. It is also reported that, in general, anions provide a more striking effect than cations [51]. This aspect was confirmed in our work: similar results were obtained when different cations were exchanged in UCONphosphate $\left(\mathrm{Na}^{+}\right.$and $\mathrm{K}^{+}$, Fig. 2 ) and in the PEG or UCON-sulfate ATPS
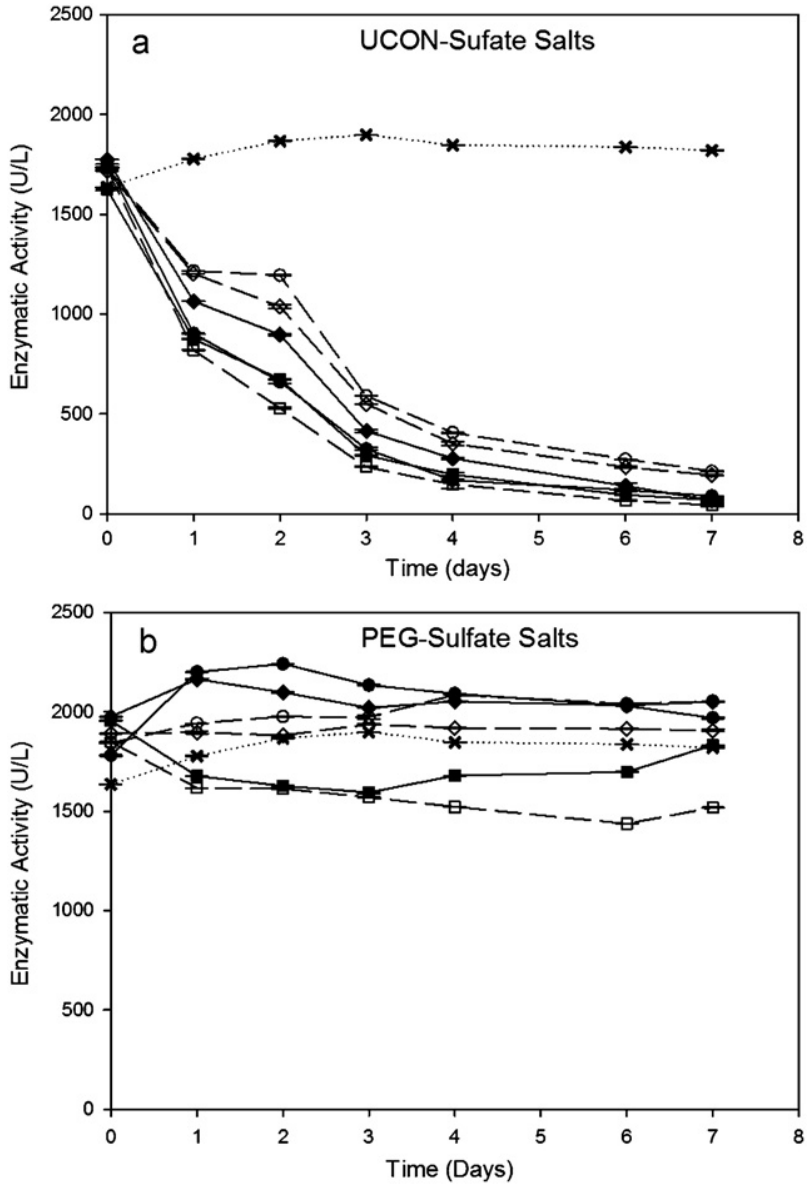

Fig. 3. Laccase stability, at room temperature, in polymer-sulfate salts ATPS: (a) UCON-sulfate salts; (b) PEG-sulfate salts. $\mathrm{Na}_{2} \mathrm{SO}_{4}$ top (filled circle); $\mathrm{Na}_{2} \mathrm{SO}_{4}$ bottom (open circle); $\left(\mathrm{NH}_{4}\right)_{2} \mathrm{SO}_{4}$ top (filled square); $\left(\mathrm{NH}_{4}\right)_{2} \mathrm{SO}_{4}$ bottom (open square); $\mathrm{Li}_{2} \mathrm{SO}_{4}$ top (filled diamond); $\mathrm{Li}_{2} \mathrm{SO}_{4}$ bottom (open diamond); Control pH 7.5 (cross).

$\left(\mathrm{Na}^{+}, \mathrm{NH}_{4}{ }^{+}\right.$and $\mathrm{Li}^{+}$, Fig. 3). However, a more remarkable effect was observed when, for example, $\mathrm{Na}_{2} \mathrm{HPO}_{4}$ was replaced by $\mathrm{Na}_{2} \mathrm{SO}_{4}$ in UCON-sodium salt ATPS (Figs. 2a and 3a, respectively). According to the Hofmeister series, $\mathrm{Na}_{2} \mathrm{SO}_{4}$ is more kosmotropic than $\mathrm{Na}_{2} \mathrm{HPO}_{4}$ [44], therefore its contribution to enzyme stability should be more effective. In this work, PEG-sulfate salts provided higher enzymatic stability. Nevertheless, UCON-sulfate salts showed poor enzymatic stability.

The stability results obtained for PEG-polymer, UCON-polymer and other polymer-polymer ATPS are represented in Fig. 4a-c, respectively. As can be seen in this Figure, similar laccase stability was found for the nine polymer-polymer ATPS. When comparing PEG and UCON ATPS, only slight changes in the enzymatic stability were observed: the laccase stability obtained for PEG-polymer ATPS (Fig. 4a) were slightly better than for UCON-polymer ATPS (Fig. 4b). Furthermore, the activity variation determined for PEGpolymer ATPS was approximately the same in both phases, while for UCON-polymer ATPS some differences were found between top and bottom phases (namely for UCON-Dextran and UCONFicoll). All the UCON-polymer ATPS studied have a top phase enriched in UCON and the same happens for the PEG-polymer ATPS studied (PEG-rich phase is the top phase). Thus, the slight differences found between PEG and UCON in polymer-polymer ATPS are possibly connected with the specific composition of each equilibrium phase. The stability results presented in Fig. 4c were obtained for the polymer-polymer ATPS prepared with Dextran, Ficoll and PES. According to the results, Dextran-Ficoll ATPS 

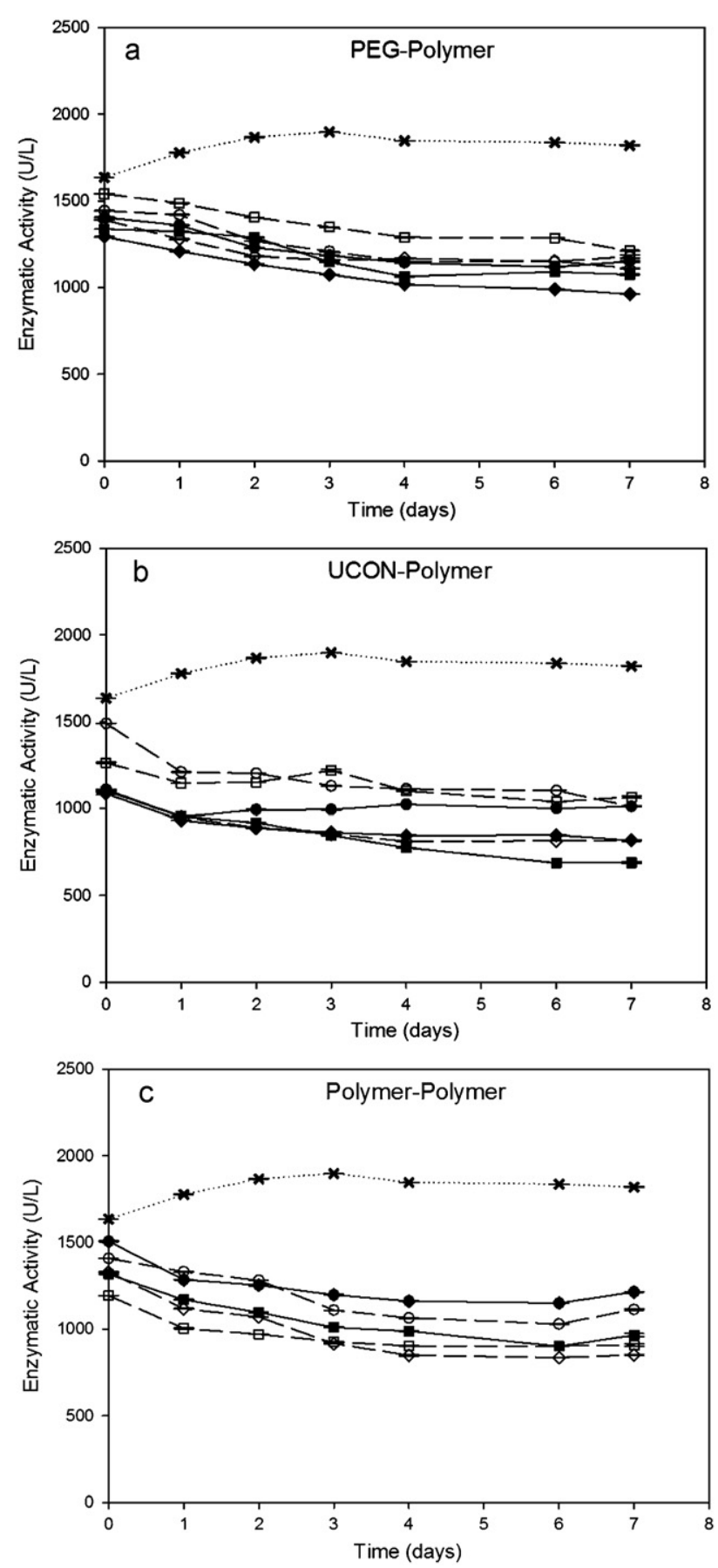

Fig. 4. Laccase stability, at room temperature, in polymer-polymer ATPS. (a) PEGpolymer: Dextran top (filled circle); Dextran bottom (open circle); Ficoll top (filled square); Ficoll bottom (open square); PES top (filled diamond); PES bottom (open diamond); Control pH7.5 (cross). (b) UCON-polymer: Dextran top (filled circle); Dextran bottom (open circle); Ficoll top (filled square); Ficoll bottom (open square); PES top (filled diamond); PES bottom (open diamond); Control pH7.5 (cross). (c) Other polymer-polymer: Dextran-Ficoll top (filled circle); Dextran-Ficoll bottom (open circle); PES-Dextran top (filled square); PES-Dextran bottom (open square); PES-Ficoll top (filled diamond); PES-Ficoll bottom (open diamond); Control pH7.5 (cross).

provided the higher enzymatic activity values during the assay. However, the activity variations obtained at the end of the assay for Dextran-Ficoll, PES-Dextran and PES-Ficoll were very similar and no relevant differences were observed between top and bottom phases. In addition, it was found that all the polymers used to form polymer-polymer ATPS contribute to keep laccase stability. However, this type of ATPS has some disadvantages related with the price and viscosity of most of the polymers used. Comparatively, polymer-salt ATPS are cheaper and present a lower viscosity, which facilitates the separation process.

\section{Conclusions}

Laccase partition coefficients were experimentally determined, at $23^{\circ} \mathrm{C}$, in 21 different ATPS (12 polymer-salt and 9 polymer-polymer ATPS). For some biphasic systems (UCONphosphate salts and PEG-Na $\mathrm{SO}_{4}$ ), different tie-line lengths were tested and it was observed that partition coefficients were only slightly affected by the changes in the ATPS composition. However, when the type of ATPS constituents (polymers and salts) was changed, more evident variations in laccase partition coefficients were produced. UCON- $\mathrm{K}_{2} \mathrm{HPO}_{4}$ was the most effective ATPS for laccase extraction $(K=0.272)$. Nevertheless, UCON-NaPB and UCON- $\mathrm{Na}_{2} \mathrm{HPO}_{4}$ also provided interesting partition coefficients ( $K=0.347$ and 0.368 , respectively).

The stability studies showed that almost all the polymers used in this work contributed for laccase stabilization. The only exception was UCON in some polymer-salt ATPS, namely with sulfates, $\mathrm{KH}_{2} \mathrm{PO}_{4}$ and $\mathrm{NaH}_{2} \mathrm{PO}_{4}$. The higher hydrophobic character of UCON can be the main reason for the activity loss observed. In polymer-salt ATPS, the more kosmotropic and basic salts provided better stability results.

Considering the results obtained both for laccase partition and stability, it was found that UCON-KPB, UCON-K $\mathrm{HPO}_{4}$, UCON-NaPB, UCON-Na $\mathrm{HPO}_{4}, \mathrm{PEG}-\mathrm{Li}_{2} \mathrm{SO}_{4}$ and PES-Dextran were the most suitable ATPS for in situ laccase recovery. It is important to highlight that UCON, as a thermo-separating polymer with lower LCST, offers some advantages for polymer recycling. Finally, the high enzymatic stability observed for PEG ATPS and the efficient extraction achieved in phosphate salt ATPS suggest that PEG-phosphate salts can be an interesting ATPS to investigate in the future.

\section{Acknowledgements}

This work is supported by project PEst-C/EQB/LA0020/2011, financed by FEDER through COMPETE - Programa Operacional Factores de Competitividade and by FCT - Fundação para a Ciência e a Tecnologia, Portugal. SCS acknowledges her Ph.D. grant of FCT (SFRH/BD/43439/2008). OR and APMT acknowledge financial support of Programme Ciência 2007 and 2008, respectively, from FCT.

\section{References}

[1] A.I. Yaropolov, O.V. Skorobogat'ko, S.S. Vartanov, S.D. Varfolomeyev, Appl. Biochem. Biotechnol. 49 (1994) 257-280.

[2] E.I. Solomon, U.M. Sundaram, T.E. Machonkin, Chem. Rev. 96(1996) 2563-2605

[3] L. Gianfreda, F. Xu, J. Bollag, Biorem. J. 3 (1999) 1-26.

[4] C. Hofer, D. Schlosser, FEBS Lett. 451 (1999) 186-190.

[5] D. Schlosser, C. Hofer, Appl. Environ. Microbiol. 68 (2002) 3514-3521.

[6] J. Li-cai, H. Pei-zhi, J. Chang-hua, D. Zi-rong, Wuhan Univ. J. Nat. Sci. 5 (2000) 351-356.

[7] H. Yoshida, J. Chem. Soc. Trans. 43 (1883) 472-486.

[8] U.N. Dwivedi, P. Singh, V.P. Pandey, A. Kumar, J. Mol. Catal. B: Enzym. 68 (2011) 0117-128.

[9] C.F. Thurston, Microbiology 140 (1994) 19-26.

[10] B.R.M. Reinhammar, Biochim. Biophys. Acta 275 (1972) 245-259.

[11] S.R. Couto, J.L. Toca-Herrera, Biotechnol. Adv. 24 (2006) 500-513.

[12] S.R. Couto, J.L. Toca-Herrera, Biotechnol. Mol. Biol. Rev. 1 (2006) 115-120.

[13] A.P.M. Tavares, R.O. Cristóvão, J.M. Loureiro, R.A.R. Boaventura, E.A. Macedo, J. Chem. Technol. Biotechnol. 83 (2008) 1609-1615.

[14] P. Zucca, A. Rescigno, A. Olianas, S. Maccioni, F.A. Sollai, E. Sanjust, J. Mol. Catal. B: Enzym. 68 (2011) 216-222.

[15] A.P.M. Tavares, J.A.F. Gamelas, A.R. Gaspar, D.V. Evtuguin, A.M.R.B. Xavier, Catal Commun. 5 (2004) 485-489.

[16] M.Y. Balakshin, D.V. Evtuguin, C.P. Neto, A. Cavaco-Paulo, J. Mol. Catal. B: Enzym 16 (2001) 131-140.

[17] A.C. Bastos, N. Magan, Int. Biodeterior. Biodegrad. 63 (2009) 389-394.

[18] D.E. Dodor, H. Hwang, M. Ekunwe, I.N. Sephen, Enzyme Microb. Technol. 35 (2004) 210-217. 
[19] M.E. Çorman, N. Ozturk, N. Bereli, S. AKgol, A. Denizli, J. Mol. Catal. B: Enzym. 63 (2010) 102-107.

[20] D. Odaci, S. Timur, N. Pazarlioglu, M.R. Montereali, W. Vastarella, R. Pilloton, A. Telefoncu, Talanta 71 (2007) 312-317.

[21] J. Osiadacz, A.J.H. Al-Adhami, D. Bajraszewska, P. Fischer, W. Peczynska-Czoch, J. Biotechnol. 72 (1999) 141-149.

[22] G. Lang, J. Cotteret, Int. Pat. Appl. WO 99/36036, July 1999.

[23] P.A. Albertosson, Partition of Cell Particles and Macromolecules, third ed., John Wiley \& Sons, New York, 1986.

[24] B.Y. Zaslavsky, Aqueous Two-Phase Partitioning: Physical Chemistry and Bioanalytical Applications, Marcel Dekker Inc., New York, 1995.

[25] K. Selber, S. Muller, H. Gieren, J. Thommes, T. Sottmann, R. Strey, M. Kula, Bioseparation 10 (2001) 243-253.

[26] M.H. Abraham, A.M. Zissimos, J.G. Huddleston, H.D. Willauer, R.D. Rogers, W.E. Acree Jr., Ind. Eng. Chem. Res. 42 (2003) 413-418.

[27] P.G. Mazzola, A.M. Lopes, F.A. Hasmann, A.F. Jozala, T.C.V. Penna, P.O. Magalhaes, C.O. Ragel-Yagui, A. Pessoa, J. Chem. Technol. Biotechnol. 83 (2008) 143-157.

[28] M. Rito-Palomares, J. Chromatogr. B 807 (2004) 3-11.

[29] J. Benavides, M. Rito-Palomares, J. Chem. Technol. Biotechnol. 83 (2008) 133-142.

[30] S.C. Silvério, O. Rodríguez,J.A. Teixeira, E.A. Macedo, J. Chem. Eng. Data 55(2010) 1285-1288.

[31] M. Pereira, Y.-T. Wu, P. Madeira, A. Venâncio, E.A. Macedo, J.A. Teixeira, J. Chem. Eng. Data 49 (2004) 43-47.

[32] S.C. Silvério, P.P. Madeira, O. Rodríguez, J.A. Teixeira, E.A. Macedo, J. Chem. Eng. Data 53 (2008) 1622-1625.
[33] O. Rodriguez, S.C. Silvério, P.P. Madeira, J.A. Teixeira, E.A. Macedo, Ind. Eng. Chem. Res. 46 (2007) 8199-8204.

[34] P.P. Madeira, J.A. Teixeira, E.A. Macedo, L.M. Mikheeva, B.Y. Zaslavsky, J. Chromatogr. A 1185 (2008) 85-92.

[35] P. Ander, K. Messner, Biotechnol. Tech. 12 (1998) 191-195.

[36] J. Persson, A. Kaul, F. Tjerneld, J. Chromatogr. B 743 (2000) 115-126.

[37] S. Saeki, N. Kuwahara, M. Nakata, M. Kaneko, Polymer 17 (1976) 685-689.

[38] J. Chen, M. Lee, Enzyme Microb. Technol. 17 (1995) 1021-1027.

[39] M. Li, J. Kim, T.L. Peeples, J. Biotechnol. 93 (2002) 15-26.

[40] D. Wei, J. Zhu, X. Cao, Biochem. Eng. J. 11 (2002) 95-99.

[41] A.P.M. Tavares, M.A.Z. Coelho, J.A.P. Coutinho, A.M.R.B. Xavier, J. Chem. Technol. Biotechnol. 80 (2005) 669-676.

[42] N.K. Pazarlıoglu, M. Sariişik, A. Telefoncu, Process Biochem. 40 (2005) $1673-1678$.

[43] A. Domínguez, O. Rodríguez, A.P.M. Tavares, E.A. Macedo, M.A. Longo, M.A. Sanromán, Bioresour. Technol 102 (2011) 7494-7499.

[44] A.P.M. Tavares, O. Rodríguez, E.A. Macedo, Biotechnol. Bioeng. 101 (2008) 201-207.

[45] Y. Wu, K.E. Taylor, N. Biswas, J.K. Bewtra, Enzyme Microb. Technol. 22 (1998) 315-322.

[46] N. Caza, J.K. Bewtra, N. Biswas, K.E. Taylor, Water Res. 33 (1999) 3012-3018.

[47] P.V. Iyer, L. Ananthanarayan, Process Biochem. 43 (2008) 1019-1032.

[48] K. Modaressi, K.E. Taylor, J.K. Bewtra, N. Biswas, Water Res. 39 (2005) 4309-4316.

[49] R. Schmid, Adv. Biochem. Eng. 12 (1979) 41-118.

[50] W. Kunz, J. Henle, B. Ninham, Curr. Opin. Colloid Interface Sci. 9 (2004) 19-37.

[51] M.G. Cacace, E.M. Landau, J.J. Ramsden, Q. Rev. Biophys. 30 (1997) 241-277. 